\title{
Identifikasi Sistem Temperatur Air Umpan Deaerator pada Pembangkit Listrik Tenaga Uap
}

\author{
Apolonius A. Hariyatma*), Awang N. I. Wardana \& Ester Wijayanti \\ Jurusan Teknik Fisika, Fakultas Teknik, Universitas Gadjah Mada \\ *)apolonius.adhi@mail.ugm.ac.id
}

\begin{abstract}
Abstrak
Dinamika karakteristik temperatur air umpan pada deaerator di Pembangkit Listrik Tenaga Uap (PLTU) perlu dipahami untuk mengetahui bagaimana sistem tersebut bekerja. Deaerator merupakan tempat penghilangan kadar oksigen. Oksigen dapat menyebabkan korosi pada peralatan logam seperti boiler. Penghilangan kadar oksigen dilakukan dengan proses pemanasan air kondensat menggunakan uap ekstraksi turbin. Berdasarkan sifat oksigen yang kelarutannya akan berkurang karena kenaikan temperatur maka kadar oksigen pada deaerator akan berkurang. Salah satu cara mengetahui karakteristik temperatur air umpan yaitu dapat berasal dari model matematis. Salah satu metode mendapatkan model matematis yaitu identifikasi sistem. Identifikasi sistem melakukan estimasi parameter berdasarkan data variabel proses input dan output pada deaerator. Identifikasi sistem dalam penelitian ini menggunakan identifikasi struktur model Auto Regressive Moving Average eXogonus input (ARMAX) Multi Input Single Output. Hasil dari penelitian ini didapatkan model matematis temperatur air umpan dengan kriteria nilai MSE sebesar 1,70 x 10-3 K dan nilai Fit sebesar 83,047 \%.

Kata Kunci: Deaerator, PLTU, Temperatur Air Umpan, Identifikasi Sistem, ARMAX.
\end{abstract}

\section{Pendahuluan}

Pada Pembangkit Listrik Tenaga Uap (PLTU) batubara, semua parameter dari peralatan yang saling berkaitan harus berjalan dengan optimal. Pada PLTU terdapat sistem pemanas air umpan. Sistem pemanas air umpan berfungsi sebagai pemanas awal air umpan sebelum diumpankan ke boiler untuk menjadi main steam. Sistem pemanas air umpan memanaskan air kondensat yang berasal dari kondenser menggunakan uap ekstraski dari turbin. Secara umum sistem pemanas air umpan terdiri dari close feedwater heater dan open feedwater heater. Umumnya close feedwater heater merupakan heat exchanger shell and tube, dan open feedwater heater merupakan deaerator.

Deaerator merupakan peralatan penting dalam sistem pemanas air umpan pada PLTU. Deaerator merupakan tempat penghilangan kadar oksigen. Oksigen dapat menyebabkan korosi pada peralatan logam seperti boiler. Penghilangan kadar oksigen dilakukan berdasarkan proses deaerasi. Prinsip dari deaerasi dapat dijelaskan dengan menggunakan hukum Henry. Secara ringkas, hukum tersebut menyatakan bahwa penghilangan oksigen dan karbon dioksida dapat disempurnakan dengan pemanasan air umpan, yang akan menurunkan tekanan parsial oksigen dan karbon dioksida. Berdasarkan sifat oksigen yang kelarutannya akan berkurang karena kenaikan temperatur tersebut maka kadar oksigen pada deaerator akan berkurang. Sehingga temperatur air umpan merupakan variabel yang harus dijaga. Salah satu cara mengetahui karakteristik hubungan input-output pada suatu proses yaitu dengan memahami model matematis sistem tersebut [1]. Model matematis tersebut dapat dijadikan acuan model untuk membuat suatu simulasi proses untuk mengetahui pengaruh faktorfaktor yang mempengaruhi karakteristik peralatan tersebut dan memahami karakteristik dinamika temperatur air umpan.

Makalah ini merupakan bagian dari penelitian mengenai pemodelan matematis dan identifikasi sistem dinamika temperatur dan level air umpan pada deaerator [2]. Dalam penelitian tersebut, metode untuk memodelkan sistem deaerator sudah banyak dilakukan antara lain pemodelan matematis dan identifikasi sistem. Model matematis dalam identifikasi sistem didapatkan berdasarkan estimasi dari data input-output pada sistem tersebut. Yuri A.W [3] telah melakukan penelitian identifikasi sistem menggunakan model Auto Regressive Moving Average eXogonus input (ARMAX) berdasarkan data operasi. Khalled Elleuch [4] telah melakukan identifikasi sistem pada proses heat transfer. Gevers [5] dan Junainah Jahaya [6] dalam penelitiannya menyebutkan bahwa struktur identifikasi sistem yang baik untuk suatu sistem multi input single output adalah Auto Regressive Moving Average eXogonus input (ARMAX). Pada umumnya identifikasi sistem model ARMAX adalah suatu model yang menggambarkan model linier. Dalam penelitian Junainah Jahaya [6] dan Khalled Elleuch [4] memberikan paparan kriteria validasi identifikasi sistem adalah nilai FIT, VAF (Varaince Accounted For), MSE (Mean Square Error), dan FPE (Final Prediction Error).

Makalah ini bertujuan untuk mendapatkan model matematis temperatur air umpan menggunakan identifikasi sistem Auto Regressive Moving Average eXogonus input (ARMAX) [3,5,6]. Model matematis ini akan divalidasi menggunakan data operasi atau 
data process variable (PV). Kriteria validasi yang digunakan adalah nilai FIT dan MSE $[4,6]$.

\section{Diskusi}

Struktur dan skema deaerator ditunjukkan pada Gambar 1.

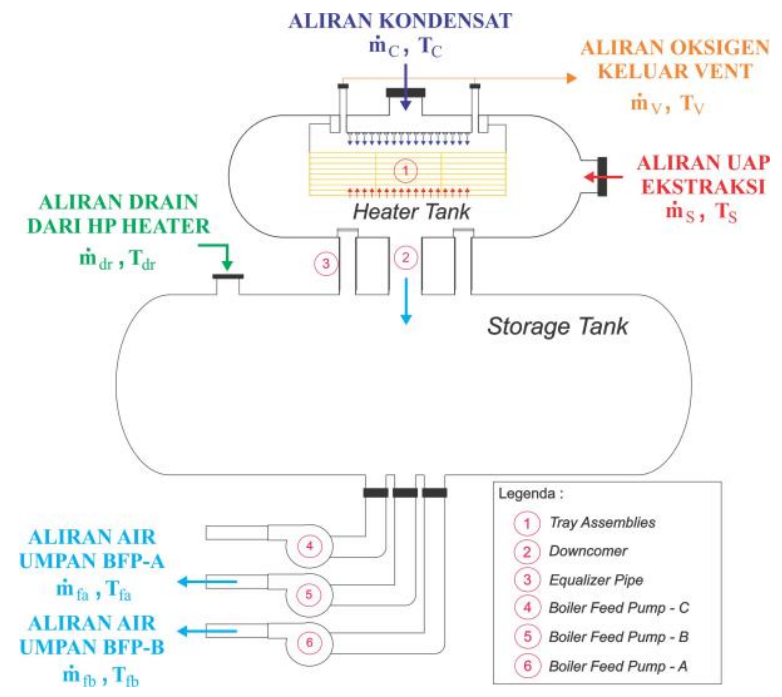

Gambar 1 struktur dan skema deaerator [2]

Pada Gambar 1, deaerator dibagi menjadi dua tangki yang saling berhubungan yaitu heater tank dan storage tank. Pada heater tank terjadi proses perpindahan panas atau deaerasi antara uap ekstraksi turbin dan kondensat pada tumpukan tray. Laju aliran kondensat akan disemprotkan melalui spray nozzle pada heater tank menjadi butiran-butiran air (droplet) dengan diameter sebesar 300-2800 mm [7]. Butiran-butiran air ini akan menyempurnakan proses perpindahan panas antara uap ekstraksi dengan aliran kondensat. Butiran-butiran air akan jatuh ke dalam lubang pada tray assembly sehingga kontak langsung secara berlawanan arah dengan uap ekstraksi. Pada deaerator, tray assembly ini tersusun secara bertingkat vertikal dan horisontal. Storage tank digunakan untuk menampung air umpan dan tidak terjadi proses perpindahan panas. Kedua tangki ini dihubungkan dengan downcomer pipe yang menyalurkan air umpan dari heater tank ke storage tank. Sedangkan equalizer pipes digunakan untuk menyeimbangkan tekanan antara kedua tangki.

Masukan pada heater tank antara lain adalah laju aliran kondensat $\left(\dot{m}_{c}\right)$ dan laju aliran uap ekstraksi turbin $\left(\dot{m}_{s}\right)$. Sedangkan keluaran pada heater tank antara lain laju aliran oksigen keluar vent $\left(\dot{m}_{v}\right)$ dan laju aliran massa air umpan ke storage tank. Masukan pada storage tank antara lain laju aliran massa air umpan dari heater tank dan laju aliran drain dari HP Heater, sedangkan keluaran pada storage tank adalah laju aliran massa air umpan melalui boiler feed pump-A $\left(\dot{m}_{f a}\right)$ dan laju aliran air umpan melalui boiler feed pump-B $\left(\dot{m}_{f b}\right)$. Boiler feed pump-C tidak dinyalakan dan berfungsi sebagai pompa standby.

Batasan masalah pada makalah ini adalah data input deaerator yang digunakan untuk identifikasi sistem adalah laju aliran massa kondensat dan temperatur uap ekstraksi dengan output temperatur air umpan dikarenakan dinamika temperatur terjadi pada output heater tank.

\subsection{Identifikasi Sistem}

Pada umumnya identifikasi sistem digunakan karena kurangnya pengetahuan tentang karakteristik fisik dari sistem yang diselidiki. Untuk melaksanakan proses identifikasi sistem diperlukan langkah-langkah sebagai berikut:
1. Pengambilan data input-output
2. Pengolahan data input-output
3. Menentukan struktur model
4. Estimasi parameter
5. Validasi model

Pada identifikasi sistem, langkah awal yang dilakukan adalah pengambilan data input-output yaitu data operasi atau process variable (PV). Selanjutnya data input dan output yang dapat dipakai dalam identifikasi sistem adalah data yang sudah direratakan nol atau mean zero. Salah satu struktur model identifikasi sistem adalah Auto Regressive Moving Average eXogeneous input (ARMAX) $[3,5,6]$. AR mendefenisikan bahwa output pada saat $t$ memiliki hubungan dengan output pada saat $t-1 \ldots t-n$. MA mendefenisikan pemodelan noise yang masuk ke sistem, dan $\mathrm{X}$ mendefenisikan bahwa sistem tidak hanya bergantung pada input pada saat $t$, tetapi juga input pada saat $t-1$. . t $n$. Metode identifikasi ARMAX dalam penelitian ini untuk identifikasi sistem temperatur air umpan pada deaerator menggunakan tools pada SCILAB. Blok diagram model ARMAX Multi Input Single Output ditunjukkan pada Gambar 2.

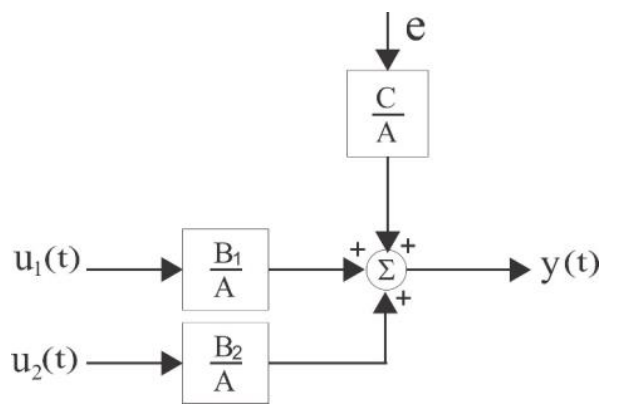

Gambar 2 blok digaram model ARMAX MISO [6]

Persamaan dari model ARMAX dua input dan satu output ditunjukkan pada Persamaan 1. 


$$
\begin{aligned}
A\left(q^{-1}\right) y(t)= & B_{1}\left(q^{-1}\right) u_{1}(t)+B_{2}\left(q^{-1}\right) u_{2}(t) \\
& +C\left(q^{-1}\right) e(t)
\end{aligned}
$$

Dimana,

$A\left(q^{-1}\right)=1+a_{1}\left(q^{-1}\right)+\ldots+a_{m}\left(q^{-m}\right)$

$B_{1}\left(q^{-1}\right)=b_{0}+b_{1}\left(q^{-1}\right)+\ldots+b_{n}\left(q^{-n}\right)$

$B_{2}\left(q^{-1}\right)=b_{0}+b_{1}\left(q^{-1}\right)+\ldots+b_{n}\left(q^{-o}\right)$

$C\left(q^{-1}\right)=1+c_{1}\left(q^{-1}\right)+\ldots+c_{p}\left(q^{-p}\right)$

Berdasarkan persamaan 1, $y(t)$ adalah output, $u(t)$ adalah input, $e(t)$ merupakan model noise yang masuk ke sistem. Pada persamaan 2, a merupakan konstanta model $A$, dan $m$ merupakan orde model $A$. Pada persamaan $3, b$ merupakan konstanta model $B$, dan $n$ dan $o$ merupakan orde model $A$. Pada persamaan $5, c$ merupakan konstanta model $C$, dan $p$ merupakan orde model C. $q^{-i} y(t)$ merupakan backwards operation yaitu $q^{-i} y(t)=y(t-i)$

\subsection{Metode Recursive Least Square}

Metode yang digunakan dalam identifikasi sistem ARMAX adalah metode Recursive Least Square. Recursive Least Square mengartikan bahwa estimasi parameter tidak hanya bergantung pada data ke- $t$ tetapi bergantung pada $t-1$. . t $t-n$ sehingga perhitungan parameter estimasi pertama dipakai dalam perhitungan data kedua, dan seterusnya. Fungsi estimasi parameter ditunjukkan pada Persamaan 7 [1].

$\hat{\theta}(t)=\hat{\theta}(t-1)+\hat{P}(t) \times \varphi(t) \times\left[y(t)-\varphi^{T}(t) \times \hat{\theta}(t-1)\right]$

Berdasarkan Persamaan 7, $\hat{P}(t)$ adalah matriks covariance yang ditunjukkan pada pada Persamaan 8 [1].

$\hat{P}(t)=\left[\hat{P}(t-1)-\frac{\hat{P}(t-1) \times \varphi(t) \times \varphi^{T}(t) \times \hat{P}(t-1)}{1+\varphi^{T}(t) \times \hat{P}(t-1) \times \varphi(t)}\right]$

Berdasarkan Persamaan 8, $\varphi(t)$ adalah konstanta estimasi parameter yang merepresentasikan data input dan output yang digunakan dalam perhitungan recursive. Sedangkan $\varphi^{T}(t)$ adalah transpose dari matriks $\varphi(t)$. Fungsi dari $\varphi(t)$ ditunjukkan pada Persamaan 9.

$\varphi(t)=\left[\begin{array}{c}-y(t-n a: t-1)^{T} \\ u_{1}\left(t-n b_{1}-n k: t-n k\right)^{T} \\ u_{2}\left(t-n b_{2}-n k: t-n k\right)^{T} \\ e p s(n-n c+1: n)^{T}\end{array}\right]$

Berdasarkan persamaan 9, $y$ adalah data output, $u$ adalah data input. na adalah orde polinomial model $\mathrm{A}, n b$ adalah orde polinomial model $\mathrm{B}, n c$ adalah orde polinomial model $\mathrm{C}, n k$ adalah data shifting, dan $n$ adalah banyaknya data perhitungan. Orde polinomial yang digunakan dalam estimasi parameter model ARMAX adalah $n a=1, n b=1$, $n b 2=1, n c=1$. Sedangkan eps adalah error prediction dari model noise pada ARMAX yang ditunjukkan ditunjukkan pada Persamaan 10 [1].

$\operatorname{eps}(t)=\left[y(t)-\varphi^{T}(t) \times \hat{\theta}(t-1)\right]$

Kriteria validasi yang digunakan adalah nilai Fit dan MSE. Persamaan MSE ditunjukkan pada persamaan $11[5,6]$.

$M S E=\frac{1}{N} \sum_{k=1}^{N}(y(k)-\hat{y}(k))^{2}$

Sedangkan persamaan Fit atau kesesuaian kurva ditunjukkan pada persamaan 12 [5,6].

Fit $=100 \% \times\left[1-\frac{\|y(k)-\hat{y}(k)\|}{\|y(k)-\bar{y}(k)\|}\right]$

Berdasarkan persamaan 11 dan 12, $y(k)$ adalah data keluaran, $\hat{y}(k)$ adalah data keluaran prediksi. Secara ringkas error kuadrat rata-rata merupakan rata-rata dari kuadrat selisih data keluaran $(y(k))$ dengan data prediksi $(\hat{y}(k))$ dibagi jumlah data $(N)$. Sedangkan, kesesuaian kurva merupakan satu dikurang panjang matriks selisih data keluaran $(y(k))$ dengan data prediksi dibagi panjang matriks selisih data keluaran $(y(k))$ dengan rata-rata data keluaran $(\bar{y}(k))$ dikali 100\%.

\subsection{Hasi}

Identifikasi linier untuk sistem temperatur air umpan menghasilkan grafik prediksi keluaran temperatur air umpan pada deaerator yang ditunjukkan pada Gambar 3.

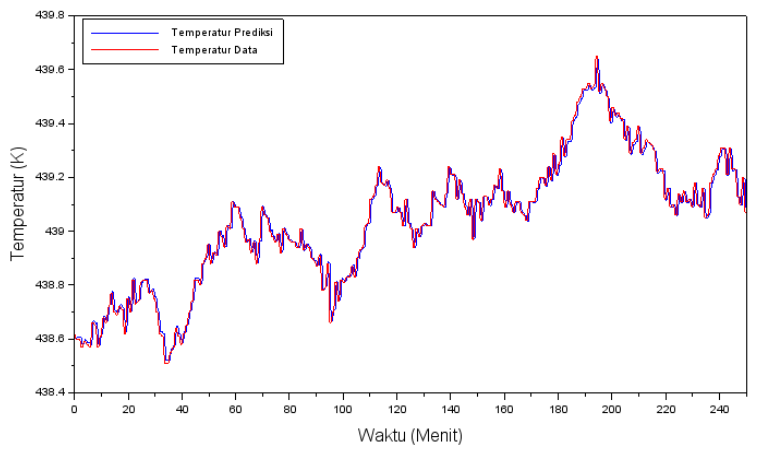

Gambar 3 grafik identifikasi sistem temperatur air umpan

Identifikasi sistem temperatur air umpan menghasilkan estimasi parameter yang ditunjukkan pada persamaan 13.

$$
\begin{aligned}
T_{F}(t) & =\frac{0,00337}{z-0,973} \dot{m}_{c}(t)+\frac{-0,00215}{z-0,973} T_{S}(t) \\
& +\frac{z+0,0223}{z-0,973} e(t)
\end{aligned}
$$

Berdasarkan parameter estimasi tersebut didapatkan nilai MSE temperatur air umpan $\left(T_{F}\right)$ sebesar $1,71 \times 10^{-3} \mathrm{~K}$. Selain itu, didapati nilai kesesuaian kurvanya sebesar 83,047\%. Rata rata 
temperatur air umpan $\left(T_{F}\right)$ prediksi bernilai 439,036 K. Sedangkan rata-rata temperatur air umpan $\left(T_{F}\right)$ data bernilai 439,037 K. Dari hasil ini dapat disimpulkan bahwa parameter estimasi yang didapat dari identifikasi sistem linier sudah merepresentasikan karakteristik temperatur air umpan $\left(T_{F}\right)$ pada kenyataan di lapangan. Parameter estimasi tersebut divalidasi dengan data variabel proses lainnya untuk menguji apakah model estimasi dapat dipakai untuk data lainnya. Hasil validasi model estimasi temperatur air umpan ditunjukkan pada Gambar 4.

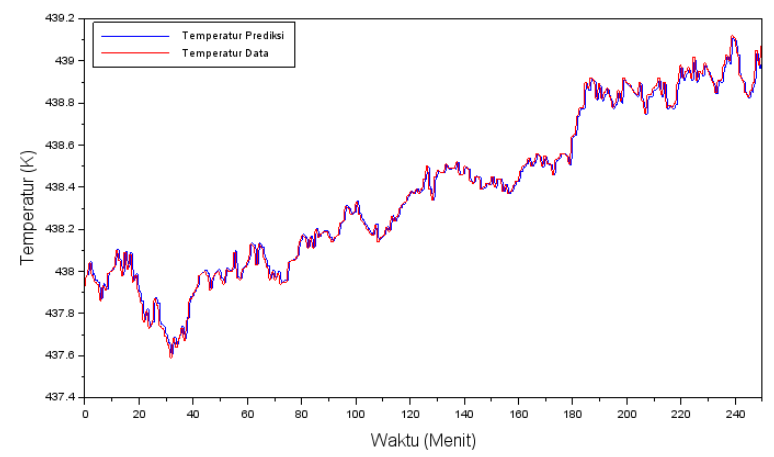

Gambar 4 grafik validasi model estimasi temperatur air umpan

Parameter estimasi yang didapat dari identifikasi linier dapat dipakai pada data validasi dengan menghasilkan nilai MSE temperatur air umpan $\left(T_{F}\right)$ prediksi sebesar 1,45 x 10-3 K dan menghasilkan kesesuaian kurva sebesar 90,181 \%. Pada hasil validasi ini didapati bahwa rata-rata pada temperatur $\left(T_{F}\right)$ air umpan prediksi bernilai 438,374 K. Sedangkan rata-rata temperatur air umpan $\left(T_{F}\right)$ data bernilai $438,376 \mathrm{~K}$. Hasil dari identifikasi sistem temperatur air umpan ditunjukkan pada Tabel 1.

Tabel 1 Ringkasan hasil identifikasi sistem

\begin{tabular}{|c|c|c|}
\hline & Data 1 & Data 2 \\
\hline MSE & $1,70 \times 10^{-3} \mathrm{~K}$ & $1,45 \times 10^{-3} \mathrm{~K}$ \\
\hline Fit & $83,047 \%$ & $90,181 \%$ \\
\hline
\end{tabular}

Berdasarkan tabel 1, didapati bahwa nilai MSE dan nilai Fit data kedua lebih baik dibandikan data pertama. Hal ini dikarenakan deviasi dari data kedua lebih kecil dibandingkan data pertama. Selain itu model estimasi ARMAX ini mempunyai grafik trend prediksi yang mengikuti grafik trend data, hal ini disebabkan model ARMAX yang merupakan auto regressive dan mendefenisikan bahwa perhitungan output prediksi pada saat $t$ menggunakan data output pada saat $t-1$.
Parameter atau model estimasi berdasarkan identifikasi sistem hanya berdasarkan data input dan output. Sehingga pada parameter estimasi tidak menerangkan fenomena-fenomena fisika yang terjadi pada sistem temperatur air umpan deaerator.

\section{Kesimpulan}

Kesimpulan pada penelitian ini menghasilkan model matematis temperatur air umpan berdasarkan identifikasi sistem yang ditunjukkan pada Persamaan 14.

$$
\begin{aligned}
T_{F}(t) & =\frac{0,00337}{z-0,973} \dot{m}_{c}(t)+\frac{-0,00215}{z-0,973} T_{S}(t) \\
& +\frac{z+0,0223}{z-0,973} e(t)
\end{aligned}
$$

Persamaan model matematis temperatur air umpan pada Persamaan 14 menghasilkan nilai MSE sebesar $1,70 \times 10^{-3} \mathrm{~K}$, dam nilai fit sebesar $83,047 \%$. Dari hasil ini model matematis atau model estimasi pada persamaan 14 sudah menunjukkan karakteristik dinamika temperatur air umpan pada deaerator.

\section{Daftar Pustaka}

[1] Lennart Ljung. System Identification: Theory for The User, Second Ed. Prentice-Hall, Inc. New Jersey. 1999.

[2] Apolonius Adhi. Pemodelan Matematis dan Identifikasi Sistem Dinamika Temperatur dan Level Air Umpan pada Deaerator. Skripsi, Universitas Gadjah Mada, Yogyakarta. 2015.

[3] Yuri A.W. Shardt dan Biao Huang. "Closed-Loop Identification Condition for ARMAX Models Using Routine Operating Data". Automatica, 47:1534-1537, 2011.

[4] Khaled Elleuch, Maher Kharrat, Abdessattar Chaari, dan Mohamed Chaabane. "Modeling and Identification of Block-Oriented Heat Transfer Process". International Journal of Information and System Sciences, 5(1):41-56, 2009.

[5] M. Gevers, L. Miskovic, D. Bonvin, dan A. Karimi. “Identification of Two-Input System: Variance Analysis”, 2005.

[6] J. Jahaya, S.W. Nawawi, dan Z. Ibrahim. "Multi Input Single Output Closed Loop Identification of Two Wheel Inverted Pendulum Mobile Robot”. IEEE Student and Development, 2011. 